\author{
A. Tamadon*, D. J. Pons, D. Clucas \\ University of Canterbury, Department of Mechanical Engineering, Christchurch 8041, \\ New Zealand
}

*abbas.tamadon@pg.canterbury.ac.nz

\title{
EBSD CHARACTERIZATION OF BOBBIN FRICTION STIR WELDING OF AA6082-T6 ALUMINIUM ALLOY
}

\begin{abstract}
Electron Backscatter Diffraction (EBSD) was used to determine microstructural evolution in AA6082-T6 welds processed by the Bobbin Friction Stir Welding (BFSW). This revealed details of grain-boundaries in different regions of the weld microstructure. Different polycrystalline transformations were observed through the weld texture. The Stirring Zone (SZ) underwent severe grain fragmentation and a uniform Dynamic Recrystallisation (DRX). The transition region experienced stored strain which changed the grain size and morphology via subgrain-boundary transformations. Other observations were of micro-cracks, the presence of oxidization, and the presence of strain hardening associated with precipitates. Flow-arms in welds are caused by DRX processes including shear, and low and high angle grain boundaries. Welding variables affect internal flow which affects microstructural integrity. The shear deformation induced by the pin causes a non-uniform thermal and strain gradient across the weld region, leading to formation of mixed state transformation of grain morphologies through the polycrystalline structure. The grain boundary mapping represents the differences in DRX mechanism I different regions of the weld, elucidates by the consequences of the thermomechanical nature of the weld. The EBSD micrographs indicated that the localised stored strain at the boundary regions of the weld (e.g. flow-arms) has a more distinct effect in emergence of thermomechanical nonuniformities within the DRX microstructure.
\end{abstract}

Keywords: AA6082-T6 aluminium alloy; bobbin friction stir welding; EBSD; grain boundary; microstructure

\section{INTRODUCTION}

\section{Friction stir welding process}

Bobbin Friction Stir Welding (BFSW) [1,2] is a thermomechanical process [3] whereby the stirring action of the tool fragments the grains into an ultrafine microstructure $[4,5]$. The frictional heat, generated between the bobbin tool and the workpiece softens the material to a plasticized flow [6,7] which is mixed by the stirring action between the advancing side (AS) and the retreating side (RS) of the rotating tool [8]. The stir-related plastic flow around the pin can also be vertically squeezed at the sub-shoulder regions of the tool $[9,10]$, restricted by the top and bottom shoulders [11-13]. By advancement of the tool through the weld-line, the 
combination of these flow regimes deposits the stirring zone (SZ) region at the trailing edge of the tool [14]. The cross-section of the BFSW weld shows the SZ at the middle, corresponding to the position of the tool action, distinguished from the Base Metal (BM) by the hourglass-shaped borders at the AS and RS of the tool position [15,16].

In addition to the heat generation, the mechanical stirring also induces strain within the $\mathrm{SZ}$ and the neighbouring regions of the $\mathrm{BM}$, leading into the formation of a transition region between the BM and the SZ [17,18]. The immediate vicinity of the SZ is known as the Thermomechanically Affected Zone (TMAZ), which is followed by the Heat Affected Zone (HAZ) towards the BM $[19,20]$. Both of these two regions are considered the transition region of the BSFW weld structure, where the grain distortion forms a transitional morphology distinct from the BM and SZ microstructures [21,22].

Thermomechanical behaviour of the BFSW is different from Conventional FSW (CFSW). In particular, in the former the symmetrical shape of the stirring zone and the formation of the flow-arms at the borders of the weld region indicate different flow behaviour $[23,24]$. This is because of the specific geometry of the bobbin-tool, whereby the interaction between the tool and substrate generates the flow-arms at the edge of the hourglass-shaped borders instead of the onion rings in a basin-shaped stirring zone of the conventional FSW $[6,7,25]$. Moreover, removal of the backing anvil and its replacement by a rotating bottomshoulder increases the heat generation and hence affects the weld microstructure [5,14,26,27].

\section{Manufacturing issues}

While BFSW is well-established for softer grades of aluminium, it is problematic for the higher strength grades. The material under examination here is AA6082-T6, which is an attractive material for ship building and other structural components involving the joining of plates. Weld quality is difficult to consistently obtain using BFSW for this material. It is becoming apparent that the challenges with BFSW of AA6082-T6 relate to lack of control over the Grain-Boundary Engineering (GBE).

\section{Grain-Boundary Engineering related to manufacturing processes}

During the welding process, thermomechanical mechanisms cause dynamic recrystallisation (DRX), which in turn causes grain-scale and sub-grain-scale changes within the weld texture $[22,28]$. These microscopic features have a considerable influence on the final properties of the BFSW weld in service [22].

GBE has been applied to CFSW to study the thermomechanical nature of the weld texture [29-32]. The frictional heat input and the flow-based mechanical stirring (with its relationship to process parameters) can create a relatively complex strain distribution $[18,33]$. This can be stored through the processed material, leading to a variety of microscopic transformations through the polycrystalline lattice of the weld texture [28,30,31,34,35].

However, for AA6082-T6 welds, it is difficult to optically delineate the grain-boundaries in microstructural observations. More recently new etchants have been identified for improvement optical microscopy of the AA6082-T6 BFSW welds [15,36]. However optical metallography is unable to provide a suitable resolution in sub-grain-scale magnifications. Hence in order to better understand the thermomechanical mechanisms and their effect on the production process, it is necessary to examine the grain boundary engineering for AA6082-T6 BFSW, which has not previously been demonstrated.

This study presents a grain-boundary engineering approach to investigate the details of the thermomechanical mechanisms occurring in electron back-scatter diffraction (EBSD) micro-constituents of the BFSW weld texture for AA6082-T6 aluminium alloy. 


\section{EXPERIMENTAL}

For the weld trials, rolled plates of AA6082-T6 (Al-Si-Mg-Mn family) were used as the starting workpiece. BFSW tests were conducted using a geometrically full-featured (including threads, flats and scrolls) bobbin tool manufactured from $\mathrm{H} 13$ tool steel with hardness of 560 HV. The schematic of the bobbin tool is shown in Figure 1.

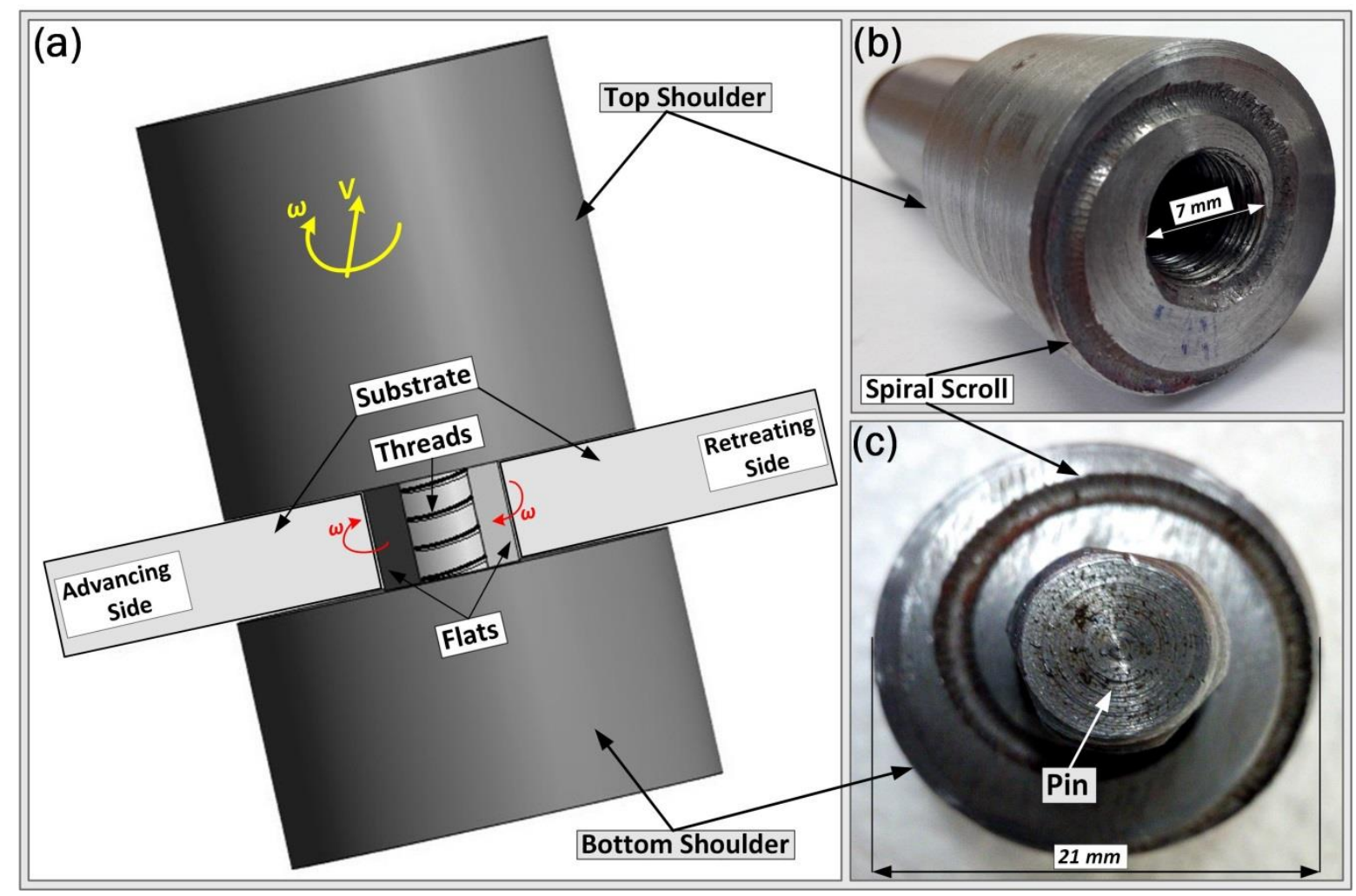

Fig. 1. Fully-featured Bobbin-Tool (tri-flat threaded pin and spiral scrolled shoulders); (a) Schematic of the bobbin-tool in interaction with the cross-section view of the substrate between the shoulders-gap,

(b) disassembled top shoulder with the drilled position of the cantered-pin,

(c) disassembled bottom shoulder and the tri-flat pin in the middle

The butt-joint weldments comprised two pieces of similar plates with dimensions of 250 $\mathrm{mm}$ (length) $\times 75 \mathrm{~mm}$ (width) $\times 6 \mathrm{~mm}$ (thickness). The compression ratio of $3.75 \%$ (difference between the actual thickness of the plate and the gap between the shoulders of the tool) was considered between the tool and workpiece to compensate the spindle forging force existing in conventional-FSW [37]. The compression ratio conserves the engagement between the plastic flow and the tool at the position of the stirring and avoiding the mass ejection. The welding trials involved a set of operation speeds; spindle rotational speed $(\omega)$ and weld travel rate $(\mathrm{V})$. In the experiments, the chosen speeds were $(\omega=400 \mathrm{rpm})$ and $(\mathrm{V}=350 \mathrm{~mm} / \mathrm{min})$. The BFSW experiments were performed on a 3-axis CNC machining centre (2000 Richmond VMC Model, 600 Group brand, Sydney, Australia) with a Fanuc control unit and 14horsepower spindle motor capacity. There were no preheating or post-weld processes before or after the welding process. The direction of tool rotation was clockwise relative to the advance direction of the welding (Figure 1). After welding the quality of joints were first checked by visual examination, and then cross sectioned by an electro-discharge wire cutting machine through the middle of the weld seam (perpendicular to the welding direction). 
The resulting surfaces were subjected to metallographic inspections. For metallographic analysis, firstly the specimens were prepared using standard mechanical polishing with different grades of $\mathrm{SiC}$ sand papers (600-grit, 800-grit and 1200-grit). To achieve a mirror surface, the micro-polishing step was conducted on a micro-cloth pad with a $3 \mu \mathrm{m}$ diamond paste, and finally a $0.05 \mu \mathrm{m}$ colloidal silica solution.

The novelty is the application of existing GBE methods to the specific case of BFSW processing of AA6082-T6. A Scanning Electron Microscope (SEM) with an EBSD detector can provide the crystallographic orientation mapping required for the study of recrystallisation. EBSD patterns can also reveal the grain-boundary and sub-grain-boundary features with high contrast at a sufficient level of magnification.

Many welds were conducted, with different process settings. Four feeding rate speeds in the range of $200-400 \mathrm{~mm} / \mathrm{min}$ and seven rotational speeds in the range of 300-600 rpm were applied to produce the BFSW weldments. While some complete welds were produced, there was also a high proportion of only partially successful welds, hence indicating a quality problem. The issue was invariably a partially successful joint with a localised defect (tunnel defect). Of these one weld samples was selected for detailed observation, corresponding to $(\omega=400 \mathrm{rpm})$ and $(\mathrm{V}=350 \mathrm{~mm} / \mathrm{min})$. This was examined in detail at one section. Different regions on the same sample were analysed, and this sometimes required repolishing (e.g. for optical vs. EBSD observation).

Our aim was to better understand the causes of the quality issues for defective welds. Other research has shown that microstructures are similar (same grain size and morphology) between defective and successful welds of this material [38-41].

Samples were examined with a scanning electron microscope (SEM) (JEOL 6100, JEOL Inc., Peabody, MA, USA) with an HKL Nordlys III EBSD detector (Oxford Instruments plc, Abingdon, UK). The EBSD maps for different regions of the weld cross section were processed using traditional clean-up procedures with HKL Tango software (HKL Channel 5 Tango software version 5.12.60.0, Oxford Instruments plc, Abingdon, UK). As the stirring was conducted over the weld locus, the grain size of the sample varied greatly from BM through to the centre of the weld. Thus, to maintain a constant number of pixels for EBSD mapping and estimation of grain size, for small grain-sized regions, a magnification step size of $0.75 \mu \mathrm{m}$ with an overall acquisition area of $\sim 1 / 16 \mathrm{~mm}^{2}$ was used. Alternatively, for large grains of BM region, a step size of $3 \mu \mathrm{m}$ with an overall acquisition area of $2 \mathrm{~mm}^{2}$ was used. All other control parameters such as binning, probe current, accelerating voltage, and exposure time were held constant. EBSD maps with obscured clarity of the Kikuchi diffraction patterns were rejected. By altering the step size, the average indexing rate of all collected samples was $97.5 \%$, where the unindexed pixels were filled in with the software. This process was consistent with how GBE has been applied to CFSW [29-32].

The crystallographic orientation is defined by a crystalline reference local frame in three orthogonal directions; rolling direction (RD), natural direction (ND) and transverse direction (TD), see Figure 2.

For transmission electron microscopy (TEM), the cross-sectioned specimen was sliced at the location of the border of the weld region, between the stirring zone and the transition region. These selected sections were mechanically ground to $0.2 \mathrm{~mm}$ thickness by a Gatan Model 691 dimple grinder. To achieve a thin section with enough transparency for TEM analysis, a Fischione twin jet electro-polishing unit was used to process the sample in a $20 \%$ methanol-diluted $\mathrm{HNO}_{3}$ solution at $18{ }^{\circ} \mathrm{C}$. TEM imaging was performed by a Philips CM120 cryo-electron microscope instrument, facilitated with the LaB6 emitter, working in accelerating voltage of $120 \mathrm{kV}$. 


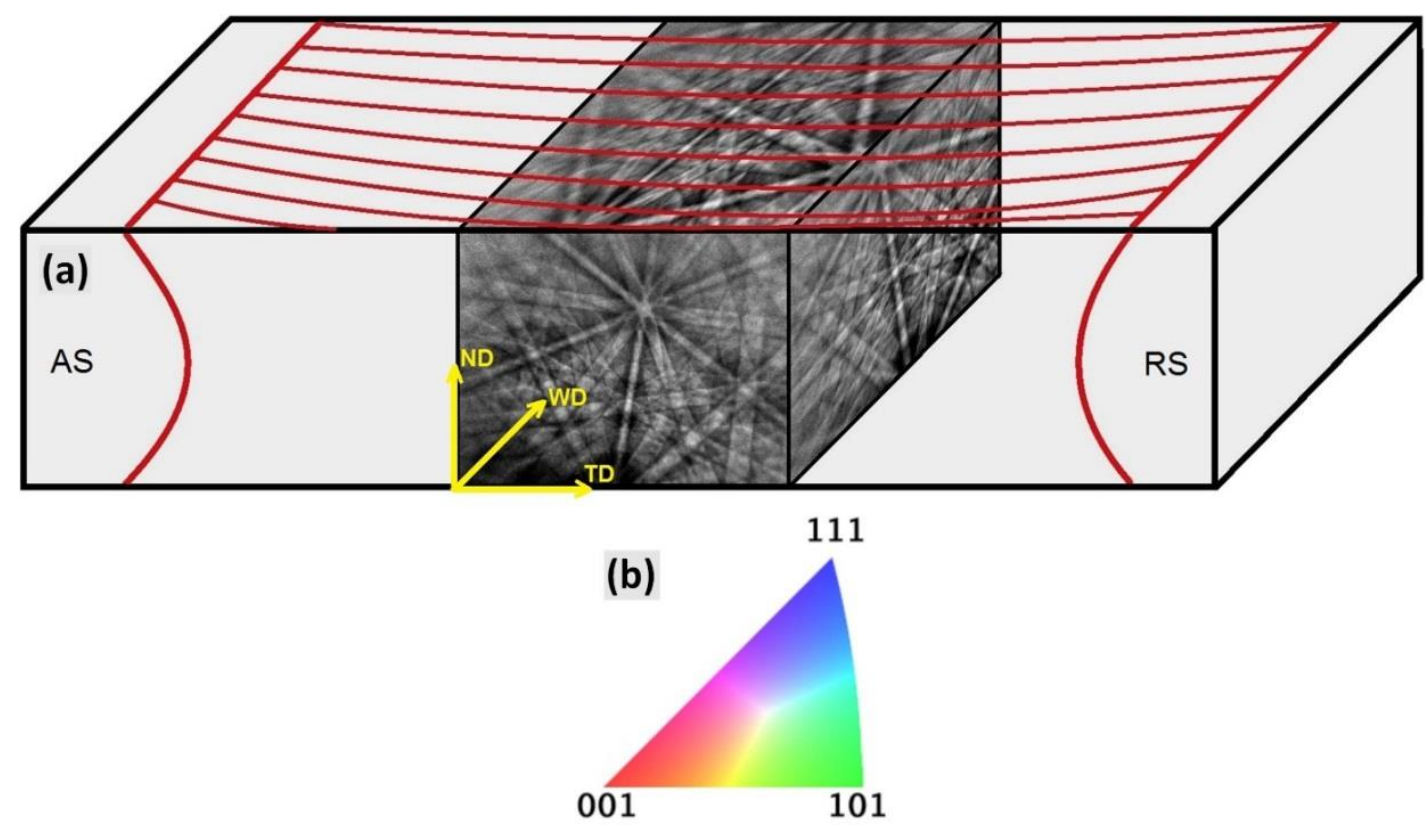

Fig. 2. EBSD analysis; (a) schematic of ED, ND and TD planes for a 3D EBSD pattern, (b) IPF triangle

\section{RESULTS AND DISCUSSION}

\section{Regions under examination}

The cross-section of the AA6082-T6 BFSW weld with the stirring zone at the middle of the weld is shown in Figure 3. Different regions of the weld are shown and numbered for further analysis, including the base metal (BM), heat-affected zone (HAZ), thermomechanically-affected zone (TMAZ), and stirring zone. Other features of the BFSW, such as the hourglass-boundary region and micro-cracks, were also selected for analysis.

The selected zones were only at the AS and mid-SZ. This is because the thermomechanical features are located here, and the literature shows that defects are invariably at the AS for BFSW [42-45]. The rotational and advancing motion of the tool on the AS border induces severe material shearing and compressive effect on the stirred mass. Consequently, the frictional heat input and plastic deformation creates a diversity of grain morphology. This comprises a transition region (HAZ, TMAZ) at the hourglass border of the weld, followed by an ultrafine morphology for the SZ.

\section{EBSD general texture evaluation}

In a polycrystalline texture, the relative difference in crystallographic orientation between two neighbouring grains is called 'Misorientation', a local transformation in the crystallographic frame [46,47]. In coordinate systems, misorientation is described as the rotating of two grains with regards to their respective crystallographic directions. Misorientation distribution is a comparative crystallographic function for the local characterisation of the grains within the texture. The EBSD analysis provides plots for graphical representation of the grain misorientation distribution in the Euler angles system, describing the misorientation probability for the three-dimensional rotation of grains. The EBSD plotting constructs a section of the crystalline texture by irregular restrictive 
boundaries between the grains. By using the pole figures and their corresponding RGB colour scheme, the crystallographic planes and orientation direction for each individual grain can be locally specified compared to the rest of texture. The colour scheme is based on a colour key triangle named the Orientation Triangle in which each of its corners has a different colour (red, blue, green) assigned to a determined crystallographic orientation $[48,49]$. The inverse pole figure (IPF) generates a colour scheme mapping for the microstructure in which the alteration of colours accurately corresponds to the orientation changes [50,51].
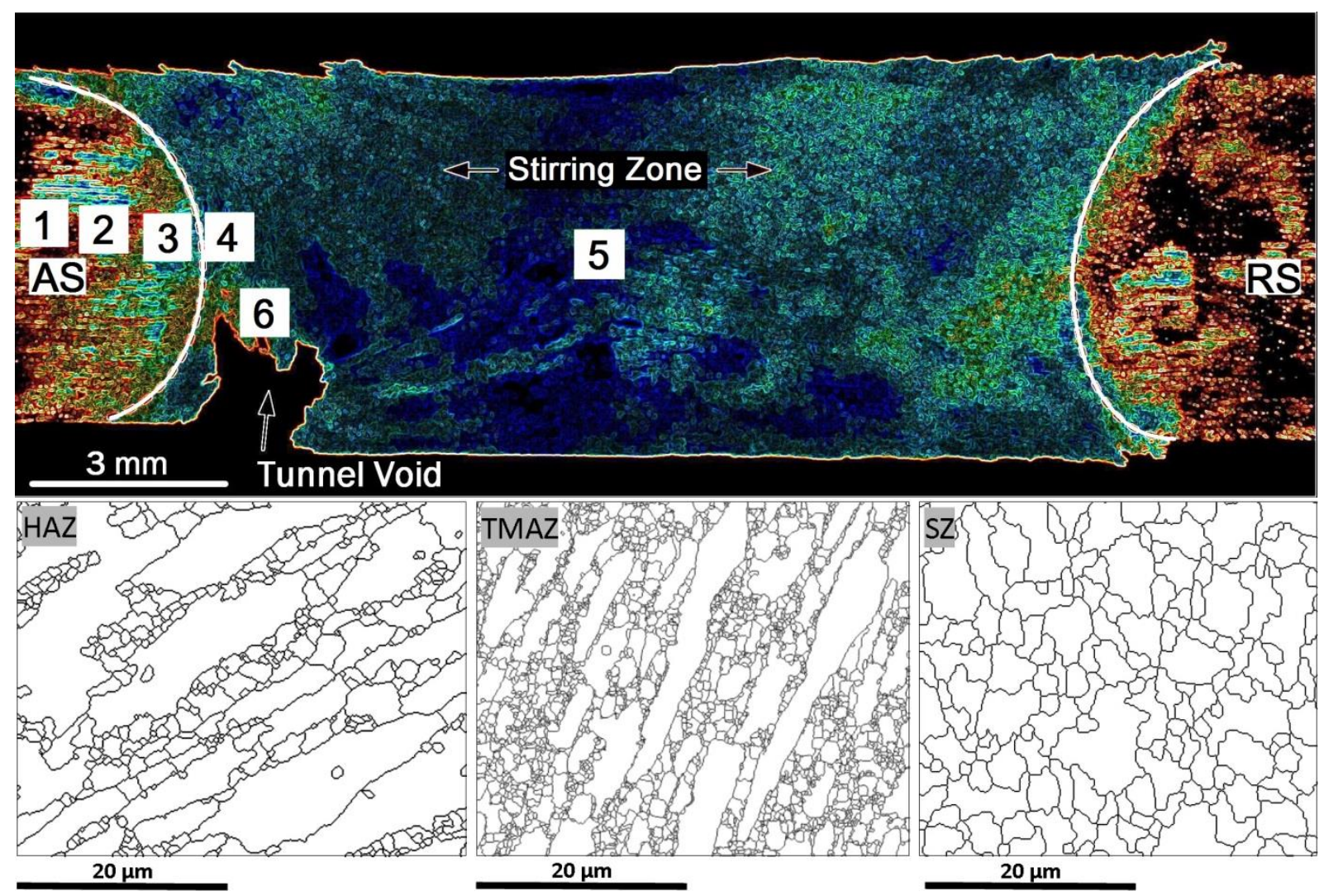

Fig. 3. Macro-etched cross-section of the AA6082-T6 BFSW weld, observed under polarized illumination. Different regions of the weld marked for further analysis; (1) base metal (BM), (2) heat-affected zone (HAZ), (3) thermomechanically-affected zone (TMAZ), (4) hourglass-boundary region, (5) mid stirring zone (mid-SZ), and (6) micro-crack region

The polycrystalline texture is formed by a colony of grains aggregated in various crystallographic orientations. While the orientation inside of each grain exhibits a minimal variation, this can easily differ for the surrounding grains. By defining a critical angle of misorientation for the volume of grains, grain-boundaries are drawn as the geometrical interface between the grains, where the area has an over-critical misorientation angle. By pixel mapping in graphical observation, the grain-boundaries can be readily identified as the spatial distribution of a randomly contoured network between the separated grains. In the inverse pole figure, the major crystallographic directions of [111], [001] and [110] are to be considered the standard for the arbitrary distribution of (hkl) poles, based on the miller indices of crystal [49,52]. The crystallographic directions determine the texture by the graphical distribution in colouring scale for the orientation maps. According to the Miller indices and based on the stereographic parameters of the crystal lattice, the coloured map overlays the [111] direct as blue, [001] as red and [110] as green, as it is standardised in the colour orientation triangle. Other orientations also are coloured in different mixtures of RGB colours, dependent on different directions intercepted between [111], [001] and [110]. Thereby, by the 
stereographic projection of crystal planes, misorientation is revealed for multiple points, distinguishable by different colours, compared with the default colours of the unit IPF triangle as the crystal directions of the normal sample. This colour mapping can clearly illustrate the crystallographic directions of the crystal lattice for grains and grain-boundaries, displaying the grain misorientation in a spatial and angular distribution through the polycrystalline texture $[47,53,54]$.

Based on the principles of the mechanical metallurgy, the strength of the texture is directly dependent on the characteristics of the grain-boundary network (morphology, density, and distribution) [55-57]. Furthermore, the grain size distribution and precipitation of secondary phase are also important microstructural features for controlling the mechanical properties during dynamic Recrystallisation [58-60].

In IPF maps, the crystallographic orientation for each individual point is shown by the colour pixels attributed to the (hkl) planes, whereby red is representative of (001), green (110), and blue (111). As the deformation and the subsequently induced strain could change the crystallographic orientation of the grains, the colour of pixels is changing through the deformed areas and demonstrates a deformation pattern for the grains. For the deformation sample, the grains misorientation can be displayed in three orthogonal directions perpendicular to the sample surface; normal direction (ND), transverse direction (TD), and rolling direction (RD). Here in BFSW sample, the RD plane is the cross-section of the weld, ND plane is the surface of the weld, and TD plane is situated at the middle of SZ across the weld centre-line. Therefore, grain recrystallisation can be studied in three different directions. This is a more accurate way of revealing the microstructural details when different transformations occur simultaneously.

To construct a 3D EBSD map, a serial sectioning procedure was conducted for the different regions of the weld in three different perpendicular planes; TD-ND, ND-WD, TDWD. The sequential section were mechanically polished and measured by the EBSD IPF mapping. Finally, the 2D EBSD maps for each section (TD-ND, ND-WD, TD-WD) were reconstructed to a 3D microstructural EBSD model. To minimise the possibility of the misinterpretation of the 3D EBSD mode due to misalignment of the measured regions, a further microscopic measurement of different modes of mapping were developed for the TDND plane for each region of the weld. By comparing of the microstructure in different maps, the inaccuracy in the misorientation details were minimised for neighbouring grain pixels in each region.

The selected frames (regions 1-6) were subject to EBSD texture evaluation and serial sectioning as described above. Results are shown in Figure 4, in the left column. This compares the different regions of the weld.

To achieve more details, the microscopic details in the TD-ND plane were further processed using other maps of EBSD (IPF X, Y, Z, Euler map, and band contrast) by the postprocessing of the indexed Kikuchi patterns. This reveals the sub-grain details of the microstructure in a higher resolution. The IPF-coloured mapping of the AA6082-T6 sample in three directions (TD-ND, ND-WD, TD-WD), across the recrystallised grains, is shown in Figure 4 (right column). The alteration of colours between adjacent pixels through the map represents the grain misorientation gradient in the texture, varied by the locally stored strain. The change in colour at the intergranular-scale reveals the position of the low-angle grain boundaries (LAGBs) or sub-grain-boundaries depending on the localised crystallographic misorientation.

The text within the image summarises the main characteristics of the grain structure at the various locations across the weld. 


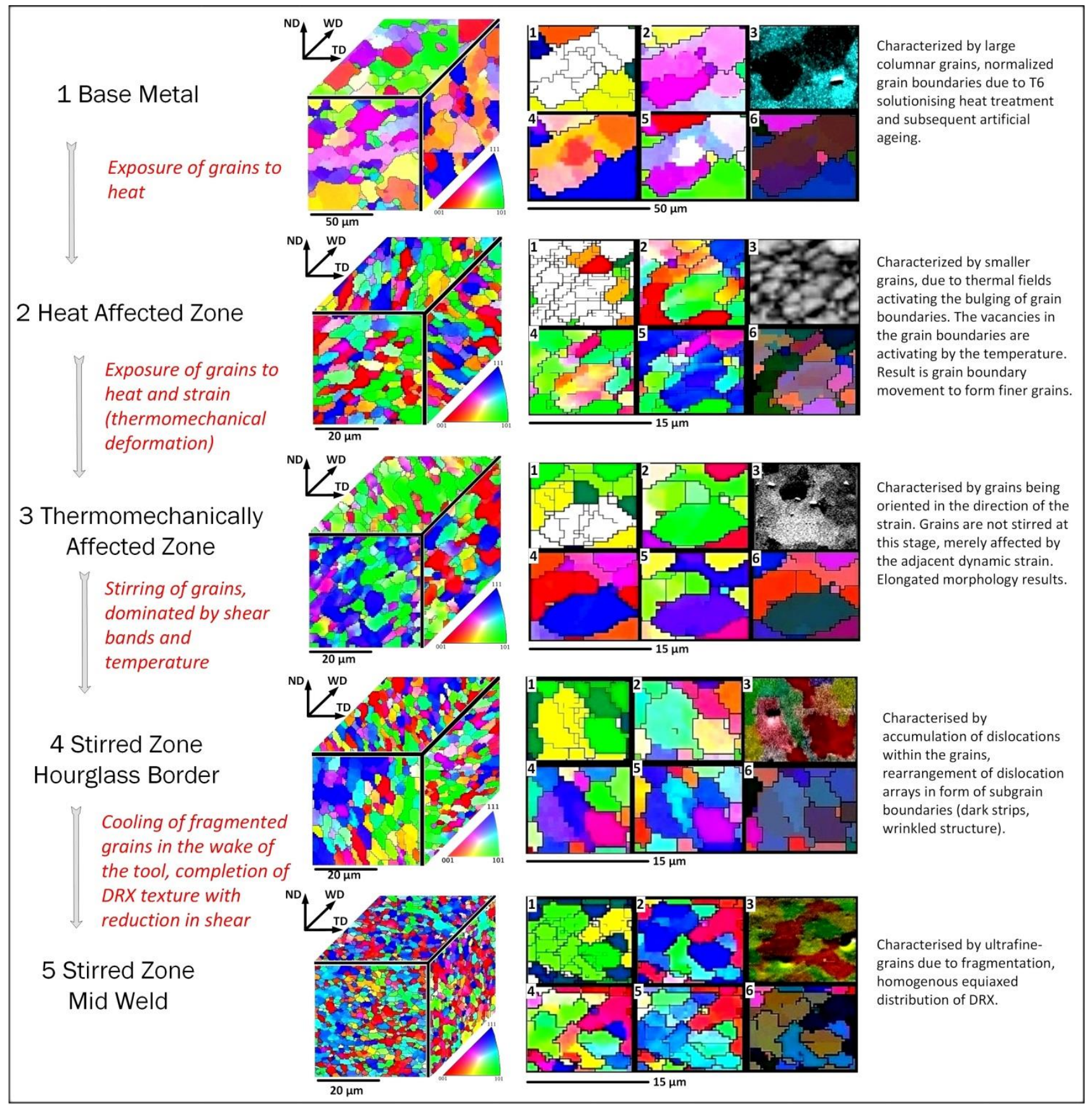

Fig. 4. 3D-constructed EBSD patterns for different regions of the weld. 3D reconstructed EBSD model and the TD-ND microscopic details (Left to right, top to bottom: 1; map 8, 2; IPF X, 3; band contrast, 4; IPF Y, 5; IPF Z, 6 ; Euler boundaries)

The equiaxed grain morphology (Region 5 in Figure 4) demonstrates a homogenized distribution of the polycrystalline grains, as a result of the severe plastic deformation leading to grain fragmentation and subsequent dynamic Recrystallisation. The grain boundaries also show the coherency of interface between the crystallites.

The Euler map displays the spatial orientation information in a basic presentation compared to the IPF maps. The IPF maps are measure the orientation based on a RGB colour key, to visualise the specific texture distribution in more detail. However, Euler maps are limited in ability to show small orientation changes. Therefore, the Euler map has less accuracy for spatial distribution of the orientation in the sub-grain-scale. The other qualitative 
measurement of EBSD is band contrast (BC) which indicates the lattice defects based on the intensification of the Kikuchi bands. The advantage of the $\mathrm{BC}$ is to show the high-angle grain boundaries. Map 8 was used to present a better contrast between High-angle and Low-angle grain boundaries.

\section{Dynamic Recrystallisation (DRX)}

While the IPF maps could specify the misorientation evolution through the weld texture, the DRX details need to be elucidated by further evaluation of the EBSD collected data. As the average grain size in the SZ reduced to the ultrafine scale, the regions of the EBSD maps need to be measured in higher magnification. Furthermore, post-processing was applied to images using HKL Channel 5 software. The microscopic maps in Figure 5 distinguish the progression of the recrystallisation through the deformed grain populations by a comparative observation in different regions of the weld texture (BM, HAZ, TMAZ, and SZ).

The post-processed maps by using the Tango software (right column in Figure 5) represent the recrystallisation detail of the grains texture after DRX. Based on the colouring method, the HKL TANGO software can modify the EBSD mapping results to a three-colour map to display the DRX details through the texture: blue for recrystallised portion (completed DRX area), yellow for substructured region (partial recrystallised), and red representative of the remaining deformed grains (named as the recovered portion where DRX did not occur). This analysis can highlight the DRX history of thermomechanically deformed material.

From the TANGO post-processed results, presented in Figure 5 (right column), it is apparent that after a general deformation the texture was predominantly in the recovery grain state (yellow fraction). Later, in DRX process, the recrystallised grains (blue fraction) are formed, which concurs with the results discussed in Figure 4.

The TANGO DRX maps elucidate the history of the orientation texture spread in different regions of the weld. First, the stirring action deforms the grains. Thereafter the recovery of the grains occurs in form of a partial recrystallisation to change the orientation from the primary deformed state (red). During the recovery phase, stress-relieving occurs and stabilises the grain texture (yellow). With appropriate thermomechanical conditions (temperature and induced strain), full recrystallisation occurs (blue grains). These grains possess a specific new orientation different from the primary deformed grains (red) and partially-DRX in the substructure grains (yellow). The comparison between different regions of the weld shows that in the SZ the recrystallised microstructure is activated to a greater extent (partial DRX in yellow, and fully-DRX in blue), with a significant reduction in grain size compared to the other region of the weld.

\section{Grain Orientation Spread (GOS) maps by Schmid Factor}

Local misorientation in deformation-induced recrystallisation can be explained by the Schmid Factor (SF) corresponding to the local deformation mode and the direction of force. By comparing the DRX map processed by HKL Channel 5 software, the grain orientation spread (GOS) analysis of the EBSD results used the Schmid factor for different regions of the weld texture, see Figure 5 (left column). The Schmid factor makes a relationship between the slip systems in crystal and the induced shear stress. Using the EBSD data it is possible to measure the stress in a crystallographic coordinate system which changes the orientation of the crystal. By post-processing of the EBSD data using the HKL software package, the alteration in the Schmid factor (SF) for neighbouring grains can be determined, which is representative of the misorientation angle. The local misorientation between the grains with range 0-15 degrees, are considered as representing the deformation history. 


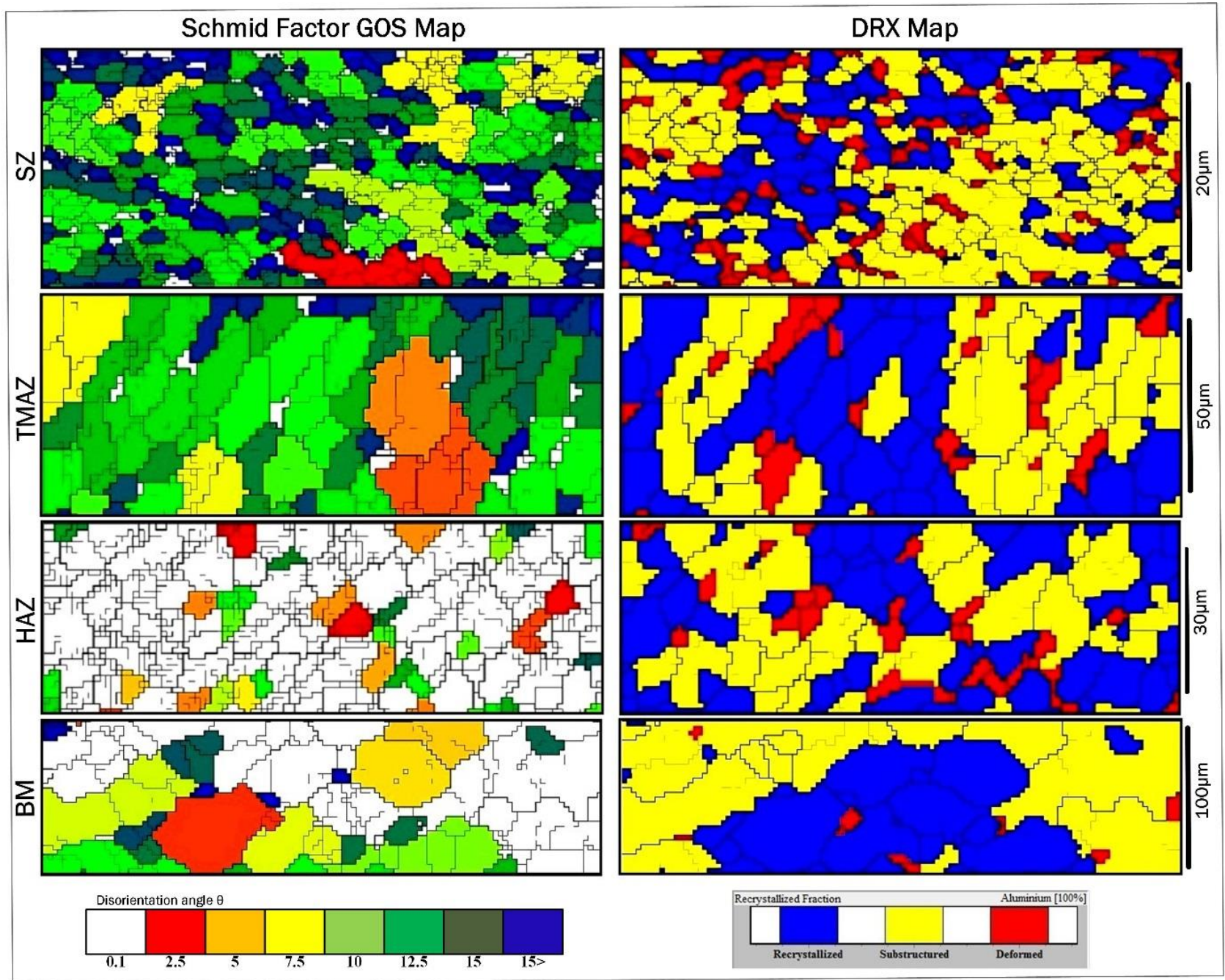

Fig. 5. Recrystallisation textures for different regions of the weld; microstructure comparison for different region of the weld, provided by Euler, IPF and recrystallisation maps

The EBSD DRX maps in Figure 5 reveal the preferred SF misorientation for emergence of sub-grain-boundaries (SGBs). The highest population of the accumulated dislocations is between 0-15 degrees. One of the most significant characteristics of the DRX transformation is the rearrangement of the grain boundaries from columnar to equiaxed. The thermal gradient and the shearing strain presumably cause this morphological variation in the grain population. The stored strain from thermal and mechanical stresses would be first released by rearrangement of the crystalline lattice via sub-grain boundaries (or LAGBs). However, in severe plastic deformation with higher levels of SF, these thermomechanical transformations can result in grain boundary movements evident in HAB misorientation. As the texture experiences greater strain, the consequences are higher progression of DRX. To extrapolate these thermomechanical features within the GOS map, the emergence of misorientation can be denoted by the colour changes of pixels corresponding to the angle of orientation content in the neighbourhood area.

The initial strain content activates the stacking fault energy as the driving force of the dislocation movement at the position of the main grain boundaries (HAGBs). This can first create a dislocation migration in low-energy array directions leading to the formation of LAGBs, and after that by additional plastic strain and movement of HAGBs. 
The GOS map of the mid-SZ indicates a highly oriented morphology with the dominating disorientation angle of $>10-15$ degrees, representative of the local misorientation. The continued DRX also induces newly strain content into the grain population which causes this disorientation.

The GOS maps in Figure 5 outline higher density of SGBs at the SZ location, identifying the preferential orientation for the accumulation of dislocations at the flow-arms. By comparing the IPF maps between the BM and SZ, a columnar-to-equiaxed transition (CET) was identified regarding the grain morphology alterations during the DRX.

\section{Stirring Zone}

The selected frame of the mid-SZ (regions 5 in Figure 3) was subject to EBSD texture evaluation; IPF colour map and corresponding grain boundary map. Results are shown in Figure 6. Equiaxed ultrafine grains in mid-SZ are observed with a random grain orientation distributed through the homogenised Al-phase texture. The grain size at the mid-SZ is about $5 \mu \mathrm{m}$ or below. The formation of ultrafine equiaxed grains in mid-SZ can be attributed to the mechanical stirring of the pin causing a uniform grain fragmentation. The fragmentation rate is presumably related to the speed ratio, $\omega / V$.

Compared to the other weld regions, the SZ is observed to have a greater density of LAGBs. Our interpretation is that this arises from the higher shear and greater heat conservation in this region.

The equiaxed grains are attributed to grain breakup during the stirring action, via the formation of micro-shear bands across the large grains. During the dynamic recrystallisation process, the internal shear combined with the temperature causes the formation of distinct smaller grains via production of internal HAGBs, as opposed to grain coalescence to form elongated grains. There are still LAGBs evident within the fine grains, presumably due to the large amounts of strain in the system compared to other regions of the weld.

Figures $6 c-f$ reveal the morphological comparison of the finer equiaxed grains in different regions of the SZ. The grain boundaries show a narrow grain size range of distribution below $10 \mu \mathrm{m}$ which is slightly finer than the grain size in mid-SZ (Figure 6b).

\section{Flow-arms and elongated-to-equiaxed transitions of grain-morphology}

The IPF maps for the orientation distribution are shown in Figure 7 corresponding to the transition region near the hourglass border towards the SZ. It should be noted that Figure 7 demonstrates the EBSD mapping of the Region 4 in Figure 3 for the hourglass flow-arm region at the AS border. The image shows the finer details inside the flow-arm.

The micrographs show the elongated grain morphology, representative of the flow-based stress-strain fields. The flow-arms along the hourglass-border are attributed to the relative motion between layers of material within the weld (cyclic deformation). The microscale postprocessing of the IPF colour map (Figure 7a) reveals the morphology of the elongated grain structures within the flow-arms due to this strain. The grain boundary distribution characterised in the Euler map (Figure 7b) displays polycrystalline anisotropy in grain boundary contrast for elongated grain morphology, different to the equiaxed microstructure of the SZ.

Our interpretation is that this morphological variation arises from the cyclic deformation in the SZ, driven by the induced strain and the generated heat. The heat also facilitates GBs movement and activation of the sub-grain boundaries. Consequently, during the re-cooling, the DRX causes abnormal grain growth: the stored strain tries to rearrange the crystalline 
lattice of the grains by an increase in the accumulation of dislocations and the population of sub-grain boundaries and LAGBs. This results in higher density of the SGBs, hence the observed formation of elongated grains as the flow-arms. By more absorption of thermal and mechanical strains, the LAGBs tend to change to HAGBs where the morphological alteration forms the grain misorientation.
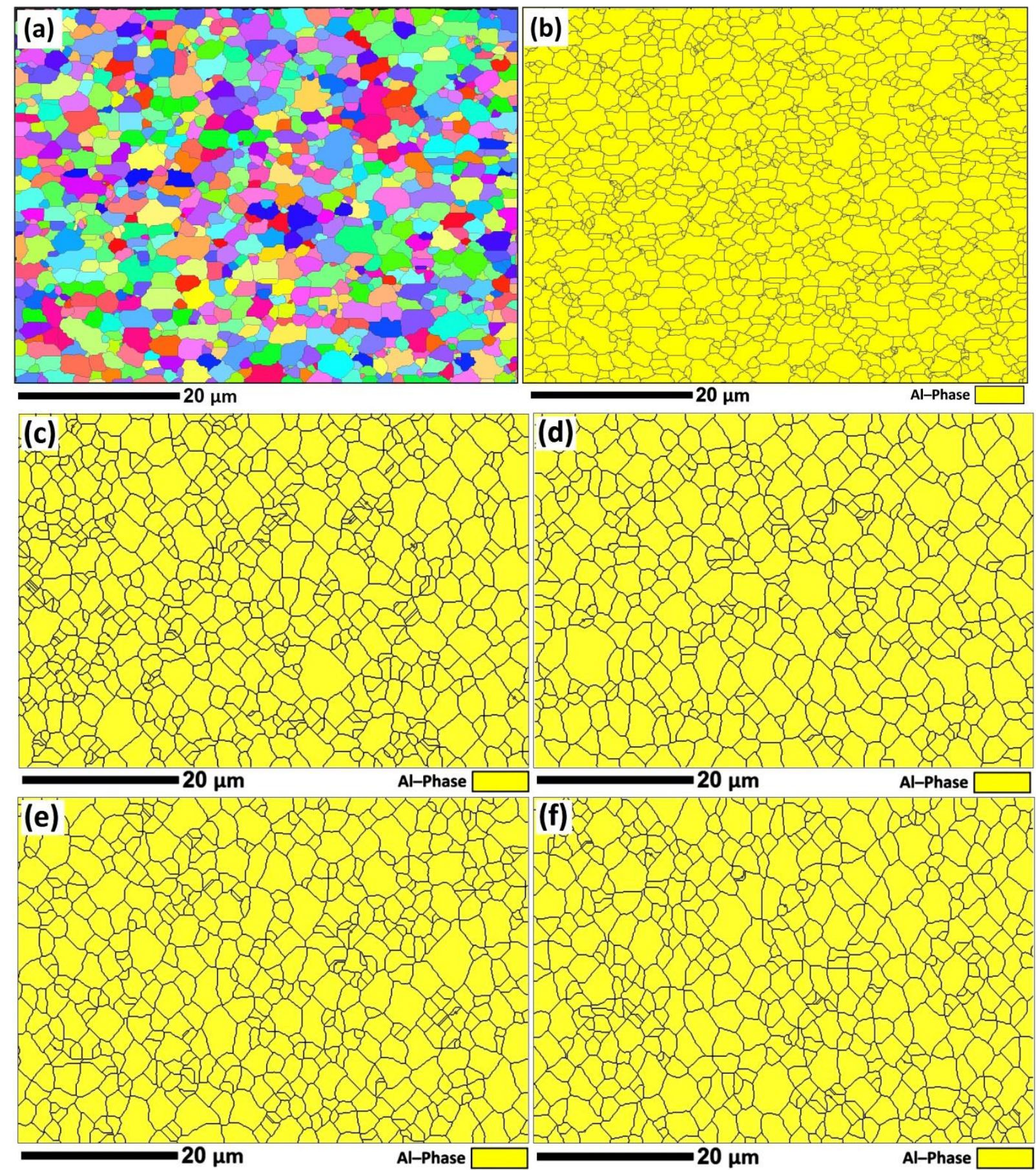

Fig. 6. EBSD analysis of the mid-SZ region; (a) IPF colour map, (b) grain boundary network through the phasecolour texture map of the corresponding IPF map in (6a), (c) equiaxed polycrystalline microstructure in topshoulder of SZ, (d) equiaxed polycrystalline microstructure in bottom-shoulder of SZ, (e) equiaxed polycrystalline microstructure in AS-border of SZ, (f) equiaxed polycrystalline microstructure in RS-border of SZ. 


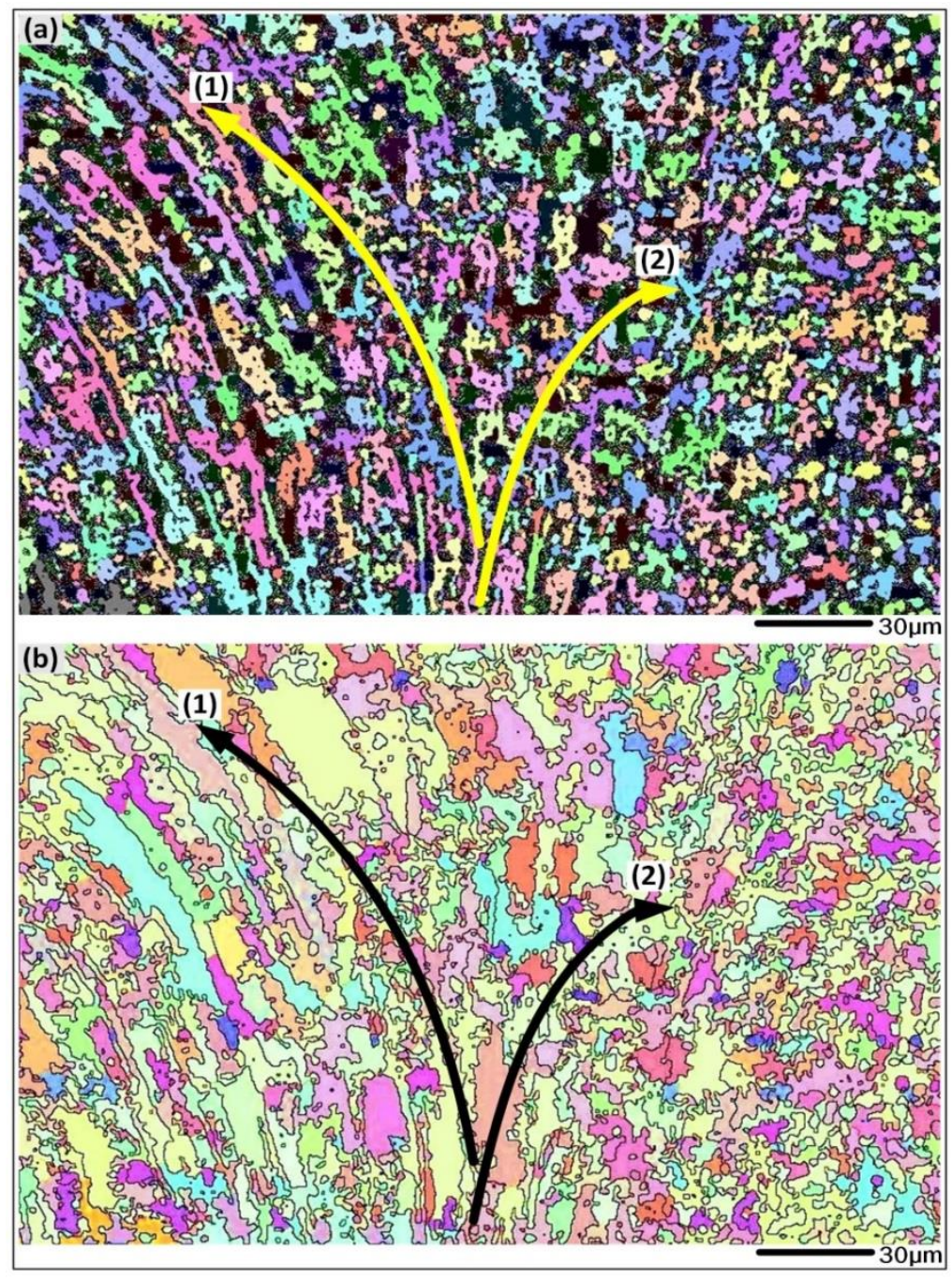

Fig. 7. The flow-arms morphology at the AS border of the SZ; (a) IPF-map, and (b) Euler Angle. (1) elongated grain morphology in hour-glass boarder region, (2) equiaxed grain morphology in stirring zone

The microstructural evolution denotes that a large portion of the grains through the crosssection experience similar effects within their physical neighbourhood. Our interpretation is that the initial strain content has dominant influence on the activation of LAGBs, while the additional plastic strain results in the advancement of grain boundary migration as the HAGBs (and the grain fragmentation).

The EBSD maps in the GOS analysis represent the local misorientation across the weld texture, where a highly oriented microstructure dominates at the borders of the SZ. This elongated grain morphology with shear direction is attributed to the higher rates of localised strain concentration at the corners of the SZ close to the hourglass borders, where the shearing bands can form the flow-arms within the grain texture during the DRX. The EBSD results suggest that the flow-arm grain morphology is also elongated parallel to the hourglass borders, oriented in (001) direction where the shear strain is in highest rate.

The microscopic observations confirm that the flow-arm recrystallised zones are dissimilar in morphology at the AS and RS of the weld. This can be attributed to the nonsymmetrical thermal flux. The more wrinkled grains texture of the AS flow-arms represents more severe shearing and higher strain imposed into the texture, compared to the morphology of the more coarse grains at the RS neighbouring with more thermal influence rather than deformation. 
At the proximity of the flow-arms, there is a grain population with different morphology which is significantly smaller than the transition region and the elongated morphology. This microscopic evolution originated from the localised heat-inducing during the DRX where the stored strain and the accumulation of the dislocations release local heating during the recooling. By absorption of this local heating via the neighbouring regions, grain boundary movement is possible which leads to the formation of the ultrafine equiaxed morphology near the shearing bands in a direction parallel to the elongated grains of the flow-arms. The extent of this region might not be symmetrical at the AS and RS borders of the weld, as during the stirring the heat flux and the stored strain content might not be equal.

The grain orientation represents the crystallographic behaviour of the deformed grains during recrystallisation mechanism. The IPF mapping denotes the grain misorientation information for: (1) whole grains in the texture contrasting by grain-boundaries as the Highangle grain boundaries (HAGBs) threshold, and: (2) the orientation alteration within the grains, indicated by the sub-grain-boundaries as the Low-angle grain boundaries (LAGBs) threshold. The thermo-mechanically induced strain during the stirring action and the postwelding re-cooling can lead to accumulation of the dislocation within the grains restricted by the grain boundaries as the High-angle grain boundaries. To reduce the internal stresses in the sub-grain scale, the dislocations adopt a self-arrangement order which leads to the formation of Low-angle grain boundaries (LAGBs) inside the grain. This can result in strain-free grains where the formation of sub-grain boundary represents a misorientation in sub-grain scale.

The formation of the LAGBs or sub-grain boundaries is highly attributed to the grain misorientation with respect to the DRX mechanism. As demonstrated in Figure 8, the grain boundary networks are observed in both transition region around flow-arms (Figures 8 a,c) and the mid-SZ in higher magnification (Figures $8 \mathrm{~b}, \mathrm{~d}$ ). The corresponding boundaries angle distributions are distinctly identified in $<2$ degrees for LAGBs in red colour, and $>15$ degrees for HAGBs in black colour. The comparing between the IPF misorientation maps in Figures 6 and 7, and the LAGBs and HAGBs distributions in Figure 8, indicate the plastic flow strain in deformation zones induced by the stirring pin is mainly responsible for the formation of the LAGBs in an angle orientation different than the HAGBs. However, the stored strain alteration and the subsequent DRX accommodated in different regions of the SZ, made a different density of the LAGBs in the various regions. Hence, it appears that the formation of the LAGBs is mainly dependent on the strain localisation during the DRX mechanism.

\section{Micro-crack formation}

The tunnel void is a large macroscopically visible feature $(1,500 \mathrm{um})$. It is also associated with flow-arms and micro-cracks (50um and smaller). The micro-cracks commence at the edge of the tunnel void, and show a multi-branched pattern extending towards the centre of the weld. The micro-cracks represent the extension of the edge of the tunnel void. Microcracks, voids, and flow-arms are typically associated together - they are part of a systematic collapse in the integrity of the internal flow. No EBSD was conducted on the tunnel void itself, as the feature is too large. However the micro-cracks were subject to detailed scrutiny.

EBSD analysis was conducted on the crack edge in the stirring zone, see Figure 9. Elemental mapping was also performed. As the scale shows, the crack is a small feature, a hairline micro-crack. It is one of many such structures. 

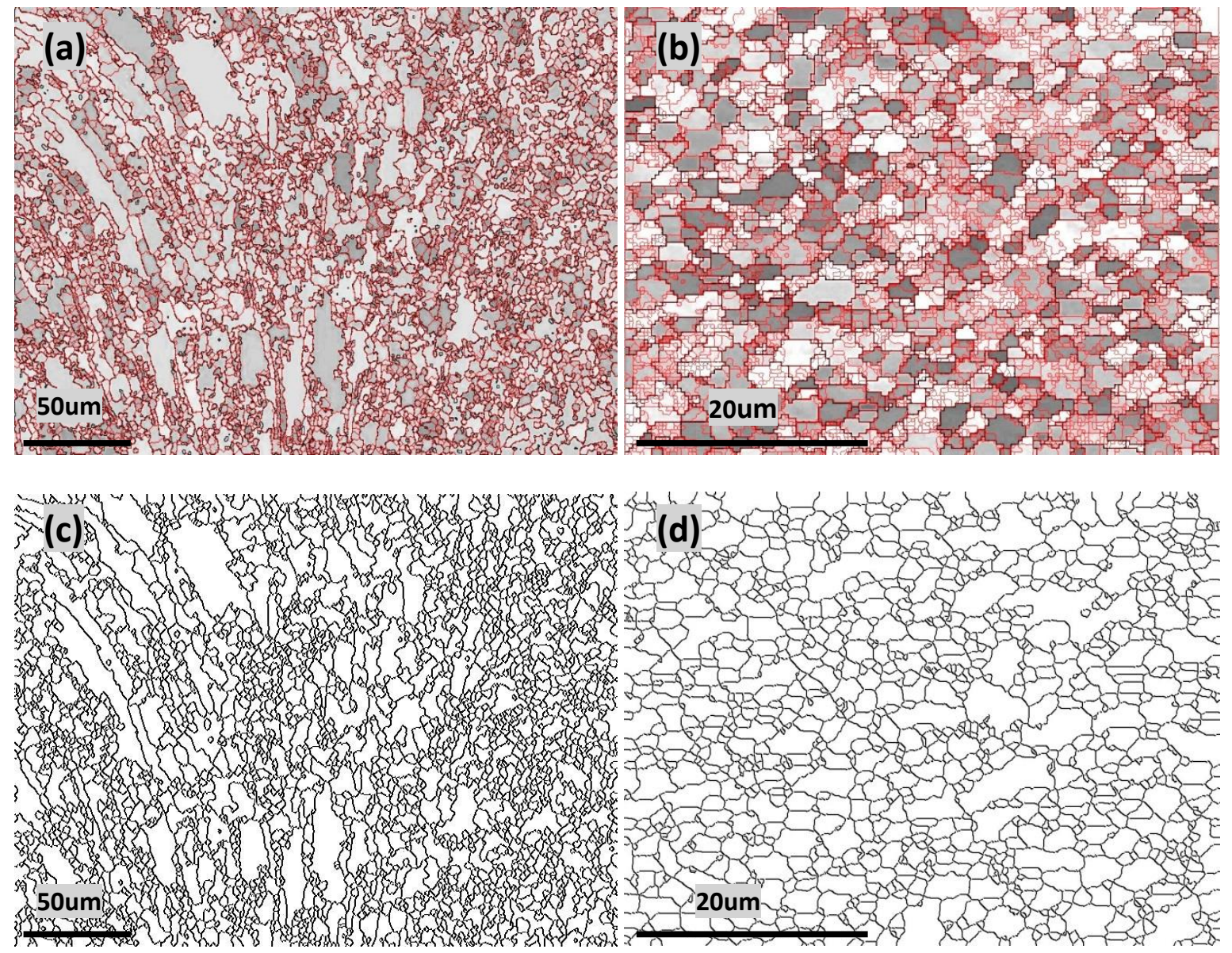

Fig. 8. EBSD orientation maps, corresponding to the misorientation angle distributions. (a, b) band contrast map for the transition region of the flow-arms and the mid-SZ, respectively. (LAGBs highlighted in red colour; with the misorientation angle of <2 degrees); (c, d) HAGBs network, for the transition region of the flow-arms and the mid$S Z$, respectively. (The misorientation angle of $>15$ degrees highlighted in black colour)

\section{Chemical composition}

Key findings are that there is a layer of yellow texture, with orientation $(001)<101>$. This is the preferred direction for aluminium oxide. The EDS confirms that this is indeed an oxide. This is a potentially novel finding. It has significant implications for the welding process, because the alumina presumably results in inclusions, restricts the reattachment of cracked surfaces and discrete packets of material in the SZ, and reduces mechanical properties.

\section{Crack formation mechanisms}

The grain structure at the crack edge has an elongated morphology compared to the smaller grains at the proximity region far away from the crack.

While these are commonly called micro-cracks, the mechanisms of formation are not fully elucidated. One line of thought is that they are cracks that propagate out from the edge of the tunnel void. This interpretation finds some support in the literature [44,45,49,61]. From this perspective the proposed explanation follows. During the crack propagation, the localised high strain deformation induces heat at the crack tip. This also induces a localised plastic deformation which causes a quick accumulation of dislocations near the crack edge. Consequently, the dislocation interaction rearranges the DRX grain evolution to heat-induced 
recrystallisation containing a large quantity of LAGBs. Furthermore, while most of the grain boundary misorientations at the crack-proximity are HAGBs, the most of the misorientation of GBs at the crack edge are LAGBs, which is representative of the typical recrystallised grains induced by deformation.

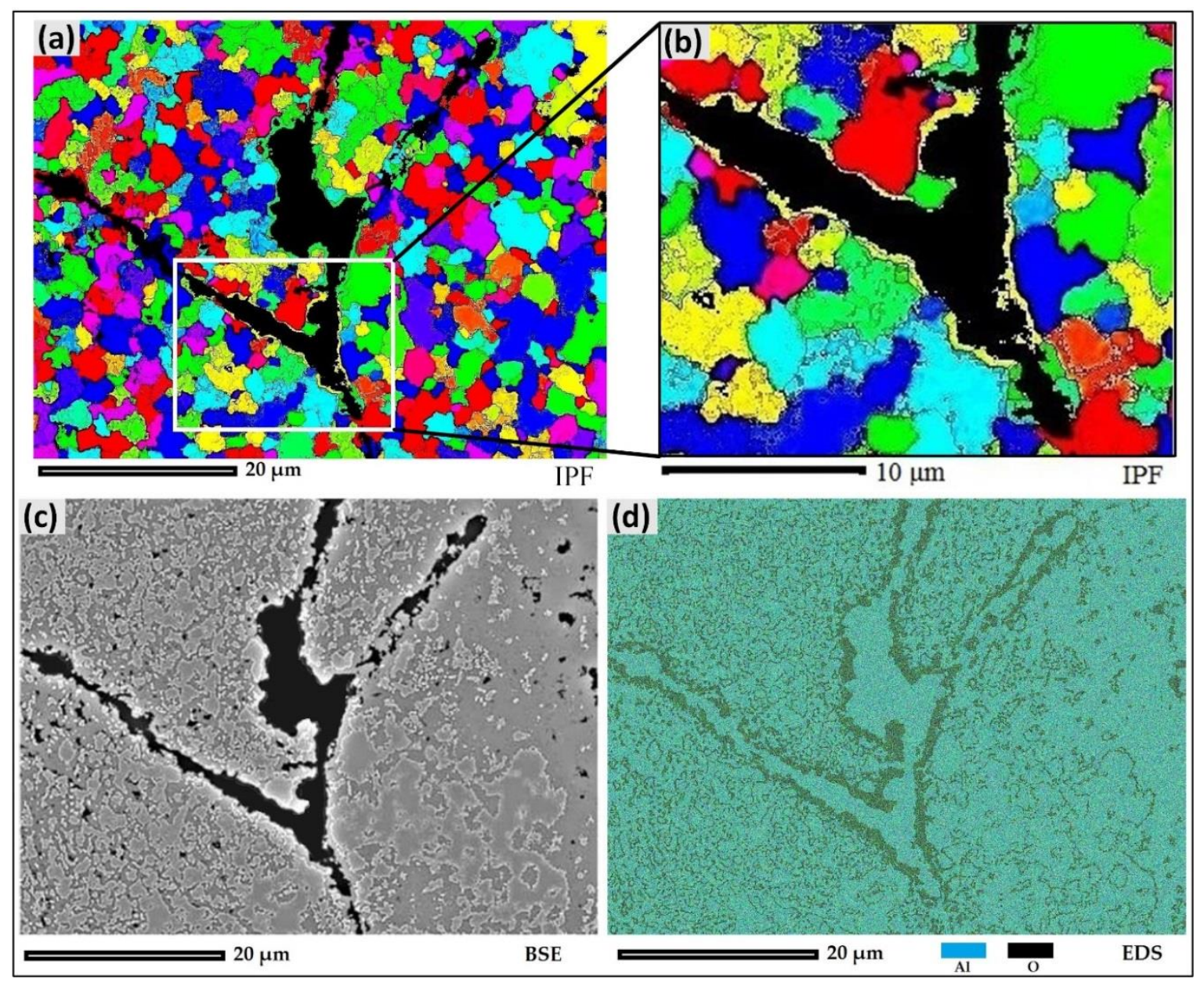

Fig. 9. Microscopic features of the micro-crack (selected from Region6, Figure 3); (a) EBSD map, (b) higher magnification of region 1 in (a), (c) BSE SEM image of the EBSD map, and (d) elemental map for the micro-crack, representative of the distribution of $\mathrm{Al}$ and $\mathrm{O}$ in micro-crack

The alternative interpretation is that these micro-cracks are instead a lack of flow bonding in the stirring process. It is already known that the material is moved around the weld in discrete packets, in a type of turbulent flow [12,44,45,61]. It is conceivable then that air enters the weld during the stirring process, and oxidises the outer layer of the hot fragments of material. These fragments are then subsequently consolidated together when they enter the advancing side of the weld. All the packets experience the same strain history, hence the similar DRX and grain morphology. However the oxide layer impedes the joining of the packets. Alternatively that trapped air resists the bonding. Then it could either be a kissing bond that is subsequently opened during re-cooling, or it may be that the material is cooling in this region and hence becoming more rigid against compaction. Our preferred explanation is the phenomenon reflects a combination of both major mechanisms: a lack of flow bonding, and a subsequent propagation of cracks through partially joined material. 


\section{Strain hardening}

The presence of the precipitates particles within the grain structure of the region of elongated grains was observed, see Figure 10a. Furthermore, the precipitates presence in subgrain scale are shown in the TEM images in Figures 10 b,c.
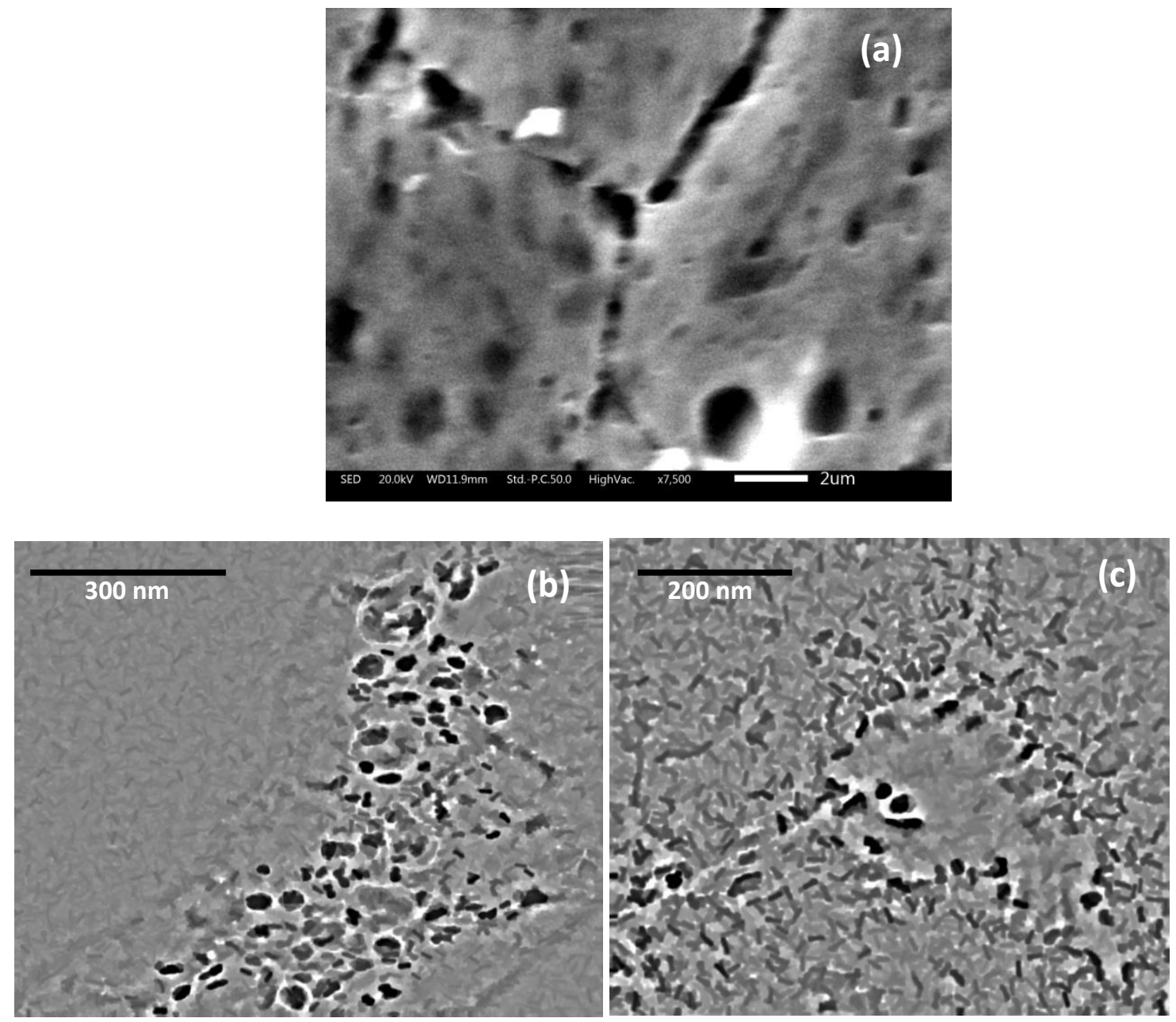

Fig. 10. Presence of the precipitates within the structure, GBs and SGBs. (a) SEM image of the elongated grains, (b) TEM image of the precipitates at the position of the GBs, (c) TEM image of the precipitates inside of the grain, at the position of the SGBs, with a distortion field around the precipitate particle

The TEM results show the deposition of the precipitates particles at the position of the GBs between the grain and within the grain at the SGBs. A distortion field around the precipitates at the SGBs position is observable, which can be representative of the strain hardening caused by the precipitates as the blocking barriers of dislocation movement.

Dislocations will accumulate first at the grain boundaries, where the precipitates are observed to be larger, and then inside the grain. The dislocations at the grain boundary contribute to the formation of HAGBs. A low-angle grain boundary is visible in Figure 10c, and is associated with a precipitate particle. Plausibly this association is due to the blocking of dislocations by the precipitate particle, and the arrangement of dislocations into the LAGBs. Blocking of dislocations at both high and low-angle boundary positions contribute to strain hardening effects.

The higher rates of the strain hardening can cause a wrinkled texture formed from the severely elongated grains. This condition can consequently lead to the crack propagation parallel to the elongated direction. 
For this microstructural evolution, the high strain rate deformation can locally induce a quick accumulation of dislocations near the GBs. Subsequently, the heat-induced recrystallisation can rearrange the dislocation arrays to sub-grain boundaries. This dislocation interaction can reduce the capacity of plasticization at the weld borders, hence strain hardening. Shear tends to nucleate precipitates at grain boundaries, and further limit dislocation mobility, hence also contributing to strain hardening.

Our interpretation is that the DRX grain refinement and the dislocation interaction can prevent the crack emergence by absorption of the strain hardening [62] and stress concentration [63] via releasing of the stored strain in the form of the LAGBs.

It is possible that the observed micro cracks are caused by the effect of strain hardening. In which case there may be benefits to post weld stress relieving by thermal conditioning.

\section{DISCUSSION}

\section{Findings}

The work makes the following original contributions to improve the understanding of the grain boundary behaviours in the BFSW welding process of AA6082-T6.

While the thermomechanical treatment can improve the ductility and strength of the material, but the severe plastic deformation and the subsequent grain Recrystallisation can cause some outcome in which affect the properties of the weld texture.

EBSD general texture evaluation; the grain boundary networks at the sub-grain scale (HAGBs and LAGBs) have been identified for multiple regions of the weld cross section, and show different morphology and spatial orientation. This is consistent with observations in the literature [49] for the crystalline lattice of the Al alloys with the FCC structure, which show the HAGBs as the main boundaries between the grains network with the misorientation angle of $>15$ degrees. The LAGBs as the direct outcome of the thermomechanical process and the subsequent DRX mechanism are within the grain structure with misorientation angle of $<2$ degrees [49].

Dynamic Recrystallisation (DRX); extensive grain refinement, reduced to the ultrafine scale, was observed in the SZ, compared to the BM texture. The microscopic evidence is of a DRX process. The alteration in grain size and morphology was observed to relate to the distance from the actual position of the severe plastic deformation (situated at the mid-SZ). According to the literature, the EBSD analysis for the AA6082-T6 FSW welds show a distinct partitioning effect of the DRX, mainly an ultrafine grain refined texture at the mid-SZ, altered to an elongated morphology on the flow-arms at the border and a transition region (TMAZ, HAZ) towards the BM. It is also supported by the previous works $[49,61,64]$ that the distance of the workpiece material from the shearing field of the welding tool is the main factor in the DRX microstructure alteration.

Flow-arms and elongated-to-equiaxed transitions of grain-morphology; different to the equiaxed microstructure of the SZ, the transition region near the hourglass border shows elongated grain morphology (flow-arms). Evidence from the EBSD micrographs shows this is caused by relative motion between layers of material within the weld (cyclic deformation), and incomplete DRX. In contrast, the grain boundary distribution in the SZ possesses polycrystalline anisotropy in equiaxed grain morphology, which is attributed to the higher temperatures contributing to a more complete DRX. This has been affirmed in the literature that the flow-arms are evident as a banded pattern compacted to each other revealed at the 
hourglass border of the weld $[49,61]$. There is still some debate about the nature of the flowarms, but the formation of this elongated morphology can be attributed to the compressive effect of the rotating tool forcing an upwards flow at the border of the solid material at the $\mathrm{BM}$ with the plasticized stirred mass. The subsequent DRX mechanism and grain refinement forms this unique elongated morphology as the intrinsic effect of the shearing stirring at the hourglass border of the weld cross-section.

Micro-crack formation; hairline micro-cracks are visible at the stirring zone near the tunnel void defect. They are distributed as narrow multi-branched features within the weld texture. The mechanism of the micro-crack formation is attributed to the lack of flow bonding during the stirring process. The formation of an oxidation layer at the edge of the crack may restrict the reattachment of cracked surfaces. This is in agreement with similar results where the dispersive flow patterns are associated with micro-cracks [52,65,66].

Precipitates and Strain hardening; the presence of precipitate particles at the position of the LAGBs and HAGBs was observed in the elongated grain structure of transition region. It is expected that these precipitates will restrict the movement of dislocations during the plastic deformation phase, hence contributing to the strain hardening effects. The further restriction of the dislocations movement can consequently lead to crack propagation parallel to the elongated direction.

As a corroborating evidence, similar results reported the precipitates within the microstructure of the AA6082-T6 alloy. It has been observed [64] that precipitation is associated with severe shearing and heat generation. More specifically, for the microstructures artificially aged by the T6 heat-treatment cycle, the FSW process can cause a precipitation through the weld texture $[67,68]$. In between, by the abnormal formation of the LAGBs/HAGBs, the sub-grain boundaries inside the grains provide new locations for the precipitating phase particles.

\section{A proposed holistic interpretation of grain boundary effects in BFSW}

Based on the EBSD information, we propose that the rotational dynamic recrystallisation is the dominant thermomechanical mechanism within the polycrystalline Al weld texture. This can be observed in the flow-arm shaped grain zone at the hourglass borders where the shear bands exist as a response to the strongly induced plastic strain. This is consistent with observations in the literature, which show the stored strain within the fragmented and stirred mass, induced by the rotational tool, provides the driving force of a DRX transformation during the re-cooling step, sufficient for a partitioning grain refinement. Consequently, different grain size and morphology are formed within the weld breadth, inside the SZ and in outer area (transition regions; TMAZ and HAZ) towards the BM [64].

The rotational dynamic recrystallisation can be explained as a continuous DRX mechanism, occurring by the evolution of low-angle grain boundaries to high-angle grain boundaries. By an increase in the degree of misorientation within the polycrystalline grain structure, the sub-grain boundaries experienced a critical mismatch in their crystal lattices. As this mismatch reached a threshold level of misorientation, the sub-grain boundaries evolve to the high-angle grain boundaries or become actual grain boundaries.

This transformation can happen when the migration of dislocations in rearranged lowangle grain boundaries is followed by shearing at the position of the main grain boundaries. Furthermore, the presence of the precipitates can pin the sub-grain boundaries in their position. Consequently, in regions exposed to higher rates of shearing, the sub-grain boundaries extend in elongated shaped grains parallel to the shearing direction. Hence a type of necklace or beading effect becomes visible, with independent grains along a shear flow line. 
In this situation, precipitates can consolidate the sub-grain boundaries in their place, which then absorb more dislocations, which eventually transform them into high-angle grain boundaries. This mechanism creates new morphology of the elongated grains, by rotation of low-angle grain boundaries, instead of grain growth. Elevated temperature and induced shearing strain activates dislocation movements and lets them rearrange themselves at the position of the sub-grain boundaries in the form of the rotational/continuous DRX of the elongated grains.

The evolution of the rotational DRX mechanism can be summarized as follows: (i) the stirring action during BFSW process can induce the strain into deformed grains and activate the dislocation interactions in low-angle grain boundaries; (ii) the generated frictional heat can develop misorientation inside the elongated cells and increase the rearrangement of the dislocation arrays; (iii) the subdivision of the low-angle grain boundaries can geometrically transform them into high-angle grain boundaries by a local crystal misorientation within the lamellar sub-grain boundaries. This can be regarded as the relaxation of the elongated subgrains during continuous DRX and formation of the elongated grains.

In contrast, the discontinuous DRX comprises the nucleation of new grains and growth at the high-angle grain boundaries as an abnormal grain growth compared to the adjacent grains.

The shear bands are regarded as the region of the localised plastic deformation $[69,70]$. During the DRX process, the nonhomogeneous deformation field (induced by the pin) causes an extensive grain deformation which leads to the large elongated grain transformation that makes up the flow-arm morphology. The micro-cracks arise between or near the shear bands, due to the effect of grain transformation and LAGBs to HAGBs changes at re-cooling.

The elongated grains at the flow-arms region inherently contain a high density of LAGBs as the sub-grain boundaries. At the end of the re-cooling procedure, some of these sub-grain boundaries which are situated close to the grain boundary interface (HAGBs) can be transmitted across the grain and gradually reinforce the neighbouring LAGBs in other grain. This mechanism can progressively increase the misorientation angle of the sub-grain boundaries and change them to HAGBs. Therefore, the continuous DRX can form larger elongated grains from the primary deformed grains with different orientations.

\section{Implications and future research opportunities}

From a production quality perspective, the tunnel void is strongly associated with poor metallurgical outcomes as evident in micro-cracks and oxidation formation [49,61,71]. Hence we can state that if a tunnel defect exists, there is a high probability of internal defects. The corollary also appears to be true: that if the tunnel void is absent, then the metallurgical defects are also absent or at least minimized. We also note that the original of the tunnel defect is primarily a consequence of the flow failure within the weld, which in turn is related to the tool geometry and weld speed parameters $(\omega, \mathrm{V})$. Thus from a practitioner perspective the appearance of a tunnel void is an important quality indication that the process is not in control.

In terms of strength, micro-cracks have large influence over the weld strength. It may be interesting to measure the density of these micro-cracks. Furthermore, there are oxide boundaries at the edge of micro-cracks, and it could be valuable to identify whether this is oxide being drawn in from the material surface or air entering between the stirred mass layers. 


\section{SUMMARY}

The objective was to examine the grain-boundary engineering caused by thermomechanical effects at the sub-grain-scale, for the difficult to weld material of AA6082T6.

The results successfully used EBSD to characterise the origin of microscopic transformations, with a focus on grain-boundaries characteristics, DRX texture, grain refinement and the relevant misorientation. Analysis was supported by SEM and TEM observations. The severe plastic deformation and fully DRX at the mid-SZ was demonstrated by an ultrafine and equiaxed grain structure, distinct from the elongated grains at the hourglass-borders of the weld region.

As a key finding of the microscopic observations, a multi-branched micro-crack feature was identified with an oxidized layer at the edge. This micro-size discontinuity phenomenon reflects the lack of flow bonding, and a subsequent propagation of the hairline-cracks through partially joined material.

Also the analyses indicate transitional elongated grain morphology (flow-arms) near the hourglass border. This anisotropic polycrystalline texture possesses specific grain morphology different to the equiaxed microstructure of the SZ. Based on evidence from the EBSD micrographs, this is attributed to the localised cyclic deformation, affected by the shear effect of the rotational bobbin-tool, and the incomplete DRX mechanism.

A mechanism is proposed for the grain boundary engineering in this material. This comprises the formation of the LAGBs/HAGBs as the thermomechanical effect of induced strain and the subsequent DRX. Further TEM observations confirm the presence of precipitate particles at the position of the LAGBs and HAGBs, at the position of the elongated grains of the flow-arms.

From a manufacturing perspective the appearance of a tunnel void is an important quality indication that the grain boundary engineering processes are not in control.

ORCID iD:

Abbas Tamadon https://orcid.org/0000-0001-7367-4207

Dirk J. Pons https://orcid.org/0000-0001-7141-0291

Don Clucas https://orcid.org/0000-0002-6724-3037

\section{REFERENCES}

1. Thomas W.; Nicholas E.; Needham J.; Murch M.; Temple-Smith P.; Dawes C. Friction stir butt welding, international patent application no. PCT/GB92 Patent application 1991.

2. Thomas W.; Nicholas, E. Friction stir welding for the transportation industries. Materials \& Design 1997, 18, 269-273.

3. Tamadon A.; Pons D.; Sued K.; Clucas D. Thermomechanical grain refinement in AA6082-T6 thin plates under bobbin friction stir welding. Metals 2018, 8, 375.

4. Threadgill P.; Leonard A.; Shercliff H.; Withers, P. Friction stir welding of aluminium alloys. International Materials Reviews 2009, 54, 49-93. 
5. Threadgill P.L.; Ahmed M.; Martin J.P.; Perrett J.G.; Wynne B.P. In The use of bobbin tools for friction stir welding of aluminium alloys, Materials Science Forum, 2010; Trans Tech Publ: pp 1179-1184.

6. Hilgert J.; Hütsch L.L.; Dos Santos J.; Huber N. In Material flow around a bobbin tool for friction stir welding, Excerpt from the Proceedings of the COMSOL Conference, 2010.

7. Hilgert J.; Schmidt H.; Dos Santos J.; Huber, N. Thermal models for bobbin tool friction stir welding. Journal of Materials Processing Technology 2011, 211, 197-204.

8. Durga B.S. Research scholar optimization of friction stir welding parameters (tool material, tool geometry and tool speed) on aluminium alloys 6061 using taguchi method" advanced research journals of science and technology (arjst) 5.2 (2018): 385-407. INTRODUCTION Friction stir welding (FSW): Friction Stir Welding (FSW), a solid state welding invented by The Welding Institute (TWI) in 1991.

9. Iwaszko J., Kudła K. Characterization of $\mathrm{Cu} / \mathrm{SiC}$ surface composite produced by friction stir processing. Bulletin of the Polish Academy of Sciences: Technical Sciences 2020, 68, 3, 555-564.

10. Kubit A.; Bucior M.; Kluz R.; Ochał K. Application of the 3d digital image correlation to the analysis of deformation of joints welded with the FSW method after shot peening. Advances in Materials Science 2019, 19, 57-66.

11. Khan N.Z.; Siddiquee A.N.; Khan Z.A.; Shihab S.K. Investigations on tunneling and kissing bond defects in FSW joints for dissimilar aluminum alloys. Journal of Alloys and Compounds 2015, 648, 360-367.

12. Tamadon A.; Pons D.; Sued K.; Clucas, D. Formation mechanisms for entry and exit defects in bobbin friction stir welding. Metals 2018, 8, 33.

13. Sued M.; Tamadon A.; Pons D. Material flow visualization in bobbin friction stir welding by analogue model. Proceedings of Mechanical Engineering Research Day 2017, 2017, 1-2.

14. Trueba L.; Torres M.A.; Johannes L.B.; Rybicki D. Process optimization in the self-reacting friction stir welding of aluminum 6061-T6. Int. J. Mater. Form. 2018, 11, 559-570.

15. Tamadon A.; Pons D.; Sued K.; Clucas D. Development of metallographic etchants for the microstructure evolution of A6082-T6 BFSW welds. Metals 2017, 7, 423.

16. Sued M.; Pons D.; Lavroff J.; Wong E.-H. Design features for bobbin friction stir welding tools: Development of a conceptual model linking the underlying physics to the production process. Materials \& Design (1980-2015) 2014, 54, 632-643.

17. Uthayakumar M.; Balasubramanian V.; Rani A.M.A.; Hadzima B. In Effects of welding on the fatigue behaviour of commercial aluminum AA-1100 joints, IOP Conference Series: Materials Science and Engineering, 2018; IOP Publishing: p 012065.

18. Kumar S.S.; Ravisankar B.; Raviram R.D. In Evaluation of mechanical properties of friction stir welded commercially pure aluminium, MATEC Web of Conferences, 2018; EDP Sciences: $p$ 04003 .

19. Murr L.; Liu G.; McClure J. Dynamic recrystallisation in friction-stir welding of aluminium alloy 1100. Journal of Materials Science Letters 1997, 16, 1801-1803.

20. Murr L.; Flores R.; Flores O.; McClure J.; Liu G.; Brown D. Friction-stir welding: Microstructural Characterization. Material Research Innovations 1998, 1, 211-223. 
21. Liechty B.; Webb B. Modeling the frictional boundary condition in friction stir welding. International Journal of Machine Tools and Manufacture 2008, 48, 1474-1485.

22. Grujicic M.; Ramaswami S.; Snipes J.S.; Avuthu V.; Galgalikar R.; Zhang Z. Prediction of the grain-microstructure evolution within a friction stir welding (FSW) joint via the use of the monte carlo simulation method. J Mater Eng Perform 2015.

23. Ramulu P.J.; Narayanan R.G.; Kailas S.V.; Reddy J. Internal defect and process parameter analysis during friction stir welding of al 6061 sheets. The International Journal of Advanced Manufacturing Technology 2013, 65, 1515-1528.

24. Shrivastava A.; Pfefferkorn F.E.; Duffie N.A.; Ferrier N.J.; Smith C.B.; Malukhin K.; Zinn M. Physics-based process model approach for detecting discontinuity during friction stir welding. The International Journal of Advanced Manufacturing Technology 2015, 79, 605-614.

25. Hilgert J.; Dos Santos J.; Huber N. Shear layer modelling for bobbin tool friction stir welding. Science and Technology of Welding and Joining 2012, 17, 454-459.

26. Dong P.; Dou Z.; Zhang P. 3D numerical simulation of temperature and stress evolution in friction stir welding of aluminum alloy. Hanjie Xuebao 2015, 36, 71-74.

27. Thomas W.; Wiesner C.; Marks D.; Staines D. Conventional and bobbin friction stir welding of $12 \%$ chromium alloy steel using composite refractory tool materials. Science and Technology of Welding and Joining 2009, 14, 247-253.

28. Fonda R.; Knipling K. Texture development in friction stir welds. Science and Technology of Welding and Joining 2011, 16, 288-294.

29. Fonda R.; Knipling K. Texture development in near- $\alpha$ ti friction stir welds. Acta Materialia 2010, $58,6452-6463$.

30. Fonda R.; Bingert J.; Colligan K. Development of grain structure during friction stir welding. Scripta Materialia 2004, 51, 243-248.

31. Fonda R.; Bingert J. Texture variations in an aluminum friction stir weld. Scripta Materialia 2007, $57,1052-1055$.

32. Fonda R.; Knipling K.; Bingert J. Microstructural evolution ahead of the tool in aluminum friction stir welds. Scripta Materialia 2008, 58, 343-348.

33. Pal S.; Phaniraj M.P. Determination of heat partition between tool and workpiece during FSW of ss304 using 3d cfd modeling. Journal of Materials Processing Technology 2015, 222, 280-286.

34. Fonda R.; Reynolds A.; Feng C.; Knipling K.; Rowenhorst D. Material flow in friction stir welds. Metallurgical and Materials Transactions A 2013, 44, 337-344.

35. Fonda R.; Knipling K.; Rowenhorst D. EDSB analysis of friction stir weld textures. JOM 2014, $66,149-155$.

36. Tamadon A. Characterization of flow-based bobbin friction stir welding process. Ph.D. Thesis, University of Canterbury, Christchurch, New Zealand, 2019.

37. Sued M.K. Fixed bobbin friction stir welding of marine grade aluminium. Ph.D. Thesis, University of Canterbury, Christchurch, New Zealand, 2015. 
38. Wen Q.; Li W.; Gao Y.; Yang J.; Wang F. Numerical simulation and experimental investigation of band patterns in bobbin tool friction stir welding of aluminum alloy. The International Journal of Advanced Manufacturing Technology 2019, 100, 2679-2687.

39. Entringer J.; Meisnar M.; Reimann M.; Blawert C.; Zheludkevich M.; Dos Santos J.F. The effect of grain boundary precipitates on stress corrosion cracking in a bobbin tool friction stir welded alcu-li alloy. Materials Letters 2019, 2, 100014.

40. Li Y.; Sun D.; Gong W. Effect of tool rotational speed on the microstructure and mechanical properties of bobbin tool friction stir welded 6082-T6 aluminum alloy. Metals 2019, 9, 894.

41. Tamadon A.; Pons D.J.; Clucas D. Thermomechanical performance of bobbin tool design as an innovative variant for friction stir welding. In Manufacturing and Design Conference (MaD 2019) Auckland, New Zealand, 2019.

42. Tamadon A.; Pons D.; Sued M.; Clucas D.; Wong E. In Analogue modelling of bobbin tool friction stir welding, Proceedings of the International Conference on Innovative Design and Manufacturing (ICIDM2016), Auckland, New Zealand, 24-26 January 2016, 2016; Auckland, New Zealand.

43. Tamadon A.; Pons D.; Sued M.; Clucas D.; Wong E. In Preparation of plasticine material for analogue modelling, Proceedings of the International Conference on Innovative Design and Manufacturing (ICIDM2016), Auckland, New Zealand, 24-26 January 2016, 2016; Auckland, New Zealand.

44. Tamadon A.; Pons D.J.; Clucas D. Structural anatomy of tunnel void defect in bobbin friction stir welding, elucidated by the analogue modelling. Applied System Innovation 2020, 3, 2.

45. Tamadon A.; Pons D.J.; Clucas D. Flow-based anatomy of bobbin friction-stirred weld; AA6082T6 aluminium plate and analogue plasticine model. Applied Mechanics 2020, 1, 3-19.

46. Cruz-Gandarilla F.; Bolmaro R.; Mendoza-León H.; Salcedo-Garrido A.; Cabañas-Moreno J. Study of recovery and first recrystallisation kinetics in CGO Fe3\% si steels using misorientationderived parameters (EBSD). Journal of Microscopy 2019, 275, 133-148.

47. Zolotorevsky N.Y.; Rybin V.; Matvienko A.; Ushanova E.; Philippov S. Misorientation angle distribution of deformation-induced boundaries provided by their EBSD-based separation from original grain boundaries: Case study of copper deformed by compression. Materials Characterization 2019, 147, 184-192.

48. Zhang L.; Wang X.; Wei X. Evolution of grain structure and texture for 6082-T6 aluminum alloy during friction stir welding. Journal of Wuhan University of Technology-Mater. Sci. Ed. 2019, 34, 397-403.

49. Tamadon A.; Pons D.J.; Clucas D.; Sued K. Texture evolution in AA6082-T6 BFSW welds: Optical microscopy and EBSD characterisation. Materials 2019, 12, 3215.

50. Pradeep S., Sharma S. K., Pancholi V. Microstructural and mechanical characterization of friction stir processed 5086 aluminum alloy. Materials Science Forum 2012, 710, 253-257.

51. Tripathi A.; Zaefferer S. On the spatial resolution of EBSD in magnesium. arXiv preprint arXiv:1906.10055 2019. 
52. Wang J.-Y.; Jiang H.-T.; Duan X.-G.; Lin H.-T.; Qiu P.; Mi Z.-L. Orientation and microstructure topology-governed crack propagation behavior in AA7021 aluminum alloys during uniaxial tension. Materials Science and Engineering: A 2019, 739, 254-263.

53. Reznik,P.; Zorina M.; Lobanov M. Role of crystallographic misorientations in the evolution of texture in FCC metals. Materials Today: Proceedings 2019, 19, 1875-1879.

54. Hong C. In Visualization of low-misorientation dislocation structures from orientation data using customized all-euler maps, IOP Conference Series: Materials Science and Engineering 2019; IOP Publishing: p 012033.

55. Dhondt M.; Aubert I.; Saintier N.; Olive J.-M. Intergranular stress corrosion cracking of friction stir welded nugget on a 2050-t8 aluminum alloy. Advances in Materials Science 2011, 11, 43-50.

56. Tashkandi M.; Al-Jarrah J.; Ibrahim M. Increasing of the mechanical properties of friction stir welded joints of 6061 aluminum alloy by introducing alumina particles. Advances in Materials Science 2017, 17, 29-40.

57. Dudzik K.; Jurczak W. Influence of friction stir welding on corrosion properties of AW-7020M alloy in sea water. Advances in Materials Science 2015, 15, 7-13.

58. Borisova Y.; Kalinenko A.; Yuzbekova D.; Mogucheva A. In The dynamic Recrystallisation behavior in al-mg alloys, Journal of Physics: Conference Series, 2019; IOP Publishing: p 012050.

59. Yang C.; Wu C.; Shi L. Phase-field modelling of dynamic Recrystallisation process during friction stir welding of aluminium alloys. Science and Technology of Welding and Joining 2019, $1-14$.

60. Zhang C.; Wang C.; Guo R.; Zhao G.; Chen L.; Sun W.; Wang X. Investigation of dynamic Recrystallisation and modeling of microstructure evolution of an $\mathrm{Al}-\mathrm{Mg}-\mathrm{Si}$ aluminum alloy during high-temperature deformation. Journal of Alloys and Compounds 2019, 773, 59-70.

61. Tamadon A.; Pons D.J.; Clucas D.; Sued K. Internal material flow layers in AA6082-T6 buttjoints during bobbin friction stir welding. Metals 2019, 9, 1059.

62. Khajehzadeh M.; Ehsani N.; Baharvandi H.R.; Abdollahi A.; Bahaaddini M.; Tamadon A. Thermodynamical evaluation, microstructural characterization and mechanical properties of B4C-TiB2 nanocomposite produced by in-situ reaction of nano-TiO2. Ceramics International 2020, 46, 26970-26984.

63. Bahaaddini M.; Baharvandi H.R.; Ehsani N.; Khajehzadeh M.; Tamadon A. Pressureless sintering of lps-SiC (SiC-A12O3-Y2O3) composite in presence of the $\mathrm{B} 4 \mathrm{C}$ additive. Ceramics International 2019, 45, 13536-13545.

64. Tamadon A.; Pons D.J.; Clucas D. AFM characterization of stir-induced micro-flow features within the AA6082-T6 BFSW welds. Technologies 2019, 7, 80.

65. Du C.; Pan Q.; Chen S.; Tian S. Effect of rolling on the microstructure and mechanical properties of 6061-T6 DS-FSW plate. Materials Science and Engineering: A 2020, 772, 138692.

66. Li G.; Zhou L.; Luo L.; Wu X.; Guo N. Microstructural evolution and mechanical properties of refill friction stir spot welded alclad 2A12-T4 aluminum alloy. Journal of Materials Research and Technology 2019, 8, 4115-4129.

67. He X.; Pan Q.; Li H.; Huang Z.; Liu S.; Li K.; Li X. Effect of artificial aging, delayed aging, and pre-aging on microstructure and properties of 6082 aluminum alloy. Metals 2019, 9, 173. 
68. Tamadon A.; Pons D.J.; Clucas D. Microstructural study on thermomechanical behaviour of 6082-T6 aluminium BFSW weld plates. In Materials@UC 2018, Christchurch, New Zealand, 2018.

69. Tamadon A.; Baghestani A.; Bajgholi M.E. Influence of WC-based pin tool profile on microstructure and mechanical properties of AA1100 FSW welds. Technologies 2020, 8, 34.

70. Tamadon A.; Pons D.; Clucas D. Analogue modelling of flow patterns in bobbin friction stir welding by the dark-field/bright-field illumination method. Advances in Materials Science 2020, 20, 56-70.

71. Tamadon A.; Abdali M.; Pons D.; Clucas D. Characterization of dissimilar Al-Cu BFSW welds; interfacial microstructure, flow mechanism and intermetallics formation. Advances in Materials Science 2020, 20, 52-78. 